\title{
Structure and stability of recombinant bovine odorant-binding protein: III. Peculiarities of the wild type bOBP unfolding in crowded milieu
}

Olga V Stepanenko, Denis O Roginskii, Olesya V Stepanenko, Irina M Kuznetsova, Vladimir N Uversky, Konstantin K Turoverov

Contrarily to the majority of the members of the lipocalin family, which are stable monomers with the specific OBP fold (a $\beta$-barrel consisting of a 8-stranded anti-parallel $\beta$ sheet followed by a short $\alpha$-helical segment, a ninth $\beta$-strand, and a disordered C-terminal tail) and a conserved disulfide bond, bovine odorant-binding protein (bOBP) does not have such a disulfide bond and forms a domain-swapped dimer that involves crossing the $\alpha$ helical region from each monomer over the $\beta$-barrel of the other monomer. Furthermore, although natural bOBP isolated from bovine tissues exists as a stable domain-swapped dimer, recombinant bOBP has decreased dimerization potential and therefore exists as a mixture of monomeric and dimeric variants. In this article, we investigated the effect model crowding agents of similar chemical nature but different molecular mass on conformational stability of the recombinant bOBP. These experiments were conducted in order shed light on the potential influence of model crowded environment on the unfolding-refolding equilibrium. To this end, we looked at the influence of PEG-600, PEG4000 , and PEG- 12000 in concentrations of 80,150 , and $300 \mathrm{mg} / \mathrm{mL}$ on the equilibrium unfolding and refolding transitions induced in the recombinant bOBP by guanidine hydrochloride. We are showing here that the effect of crowding agents on the structure and conformational stability of the recombinant bOBP depends on the size of the crowder, with the smaller crowding agents being more effective in the stabilization of the bOBP native dimeric state against the guanidine hydrochloride denaturing action. This effect of the crowding agents is concentration dependent, with the high concentrations of the agents being more effective. 


\section{Structure and Stability of Recombinant Bovine Odorant-}

\section{Binding Protein: III. Peculiarities of the Wild Type bOBP}

\section{Unfolding in Crowded Milieu}

5 Olga V. Stepanenko, ${ }^{1}$ Denis O. Roginskii, ${ }^{1}$ Olesya V. Stepanenko, ${ }^{1}$ Irina M. Kuznetsova, ${ }^{1}$

6 Vladimir N. Uversky, ${ }^{1,2, *}$ and Konstantin K. Turoverov ${ }^{1,3, *}$

$8{ }^{1}$ Laboratory of structural dynamics, stability and folding of proteins, Institute of Cytology,

9 Russian Academy of Sciences, St. Petersburg, Russia;

$10{ }^{2}$ Department of Molecular Medicine and USF Health Byrd Alzheimer's Research Institute,

11 Morsani College of Medicine, University of South Florida, Tampa, FL, USA;

$12{ }^{3}$ Peter the Great St. Petersburg Polytechnic University, St. Petersburg, Russia

14 *To whom correspondence should be addressed: VNU, Department of Molecular Medicine, 15 University of South Florida, 12901 Bruce B. Downs Blvd. MDC07, Tampa, Florida 33612, 16 USA, E-mail: vuversky@health.usf.edu; KKT, Institute of Cytology, Russian Academy of

17 Sciences, Tikhoretsky Av., 4, St. Petersburg 194064, Russia, E-mail: kkt@incras.ru

Running title: Unfolding of the recombinant bOBP in crowded environments 


\section{ABSTRACT}

23 Contrarily to the majority of the members of the lipocalin family, which are stable monomers

24 with the specific OBP fold (a $\beta$-barrel consisting of a 8 -stranded anti-parallel $\beta$-sheet followed

25 by a short $\alpha$-helical segment, a ninth $\beta$-strand, and a disordered $\mathrm{C}$-terminal tail) and a conserved

26 disulfide bond, bovine odorant-binding protein (bOBP) does not have such a disulfide bond and

27 forms a domain-swapped dimer that involves crossing the $\alpha$-helical region from each monomer

28 over the $\beta$-barrel of the other monomer. Furthermore, although natural bOBP isolated from

29 bovine tissues exists as a stable domain-swapped dimer, recombinant bOBP has decreased

30 dimerization potential and therefore exists as a mixture of monomeric and dimeric variants. In

31 this article, we investigated the effect model crowding agents of similar chemical nature but

32 different molecular mass on conformational stability of the recombinant bOBP. These

33 experiments were conducted in order shed light on the potential influence of model crowded

34 environment on the unfolding-refolding equilibrium. To this end, we looked at the influence of

35 PEG-600, PEG-4000, and PEG-12000 in concentrations of 80,150 , and $300 \mathrm{mg} / \mathrm{mL}$ on the

36 equilibrium unfolding and refolding transitions induced in the recombinant bOBP by guanidine

37 hydrochloride. We are showing here that the effect of crowding agents on the structure and 38 conformational stability of the recombinant bOBP depends on the size of the crowder, with the

39 smaller crowding agents being more effective in the stabilization of the bOBP native dimeric

40 state against the guanidine hydrochloride denaturing action. This effect of the crowding agents is

41 concentration dependent, with the high concentrations of the agents being more effective. 


\section{INTRODUCTION}

45 Classical odorant binding proteins (OBPs) are intriguing members of the large lipocalin

46 family, which, due to their ability to interact with different odorants (small hydrophobic

47 molecules of various nature and structure that have to travel from air to olfactory receptors in 48 neurones through the aqueous compartment of nasal mucus (Buck \& Axel 1991; Pevsner et al.

49 1988; Pevsner \& Snyder 1990; Snyder et al. 1989)), play important but yet not completely 50 understood role in olfaction (Pelosi 1994). Typically, OBPs are monomeric carrier proteins

51 characterized by a specific 3-D fold, known as a prototypic OBP-fold that represents a $\beta$-barrel 52 composed by a 8 -stranded anti-parallel $\beta$-sheet followed by a short $\alpha$-helical segment, a ninth $\beta$ -

53 strand and disordered C-terminal tail (Bianchet et al. 1996; Flower et al. 2000). The internal 54 cavity of the OBP $\beta$-barrel is the binding site that can interact with the odorant molecules 55 belonging to different chemical classes (Vincent et al. 2004).

Bovine OBP (bOBP) has a unique dimeric structure, which is different from the monomeric OBP fold found in the majority classical OBPs (see Figure 1) (Bianchet et al. 1996). Each protomer in the bOBP dimer forms a $\beta$-barrel via interaction with the $\alpha$-helical region of another protomer by means of the domains swapping mechanism (Bianchet et al. 1996; Tegoni et al. 1996). The domain swapping mechanism, being described for several dimeric and oligomeric proteins, is known to play important structural and functional roles (Bennett et al. 1995; van der Wel 2012). It is believed that the domain swapping causes the increase in the interface area and thereby affects the overall protein stability (Bennett et al. 1994; Liu \& Eisenberg 2002). In some cases it has been shown that the formation of the quaternary structure by means of domain swapping was responsible for the appearance of novel functions in corresponding protein monomers, functions, which were not originally present in the monomeric forms of those 
67 proteins (Liu \& Eisenberg 2002). Furthermore, early stages of the amyloid fibril formation are

68 believed to be associated with the formation of domain-swapped oligomers (van der Wel 2012).

69 Our previous studies revealed that there is a noticeable difference between the recombinant

70 bOBP and a natural form of this protein isolated from tissues (Stepanenko et al. 2014b). Here,

71 recombinant bOBP forms a stable native-like conformation with the decreased dimerization

72 potential and therefore exists as a mixture of monomeric and dimeric variants (Stepanenko et al.

73 2014b). We designated this stable recombinant bOBP state in buffered solution as a "trapped"

74 state with incorrect packing of $\alpha$-helices and $\beta$-strands within the protein globule, which may

75 interfere with the formation of the bOBP native state. This "trapped" state may be accumulated

76 because the formation of the domain-swapped dimer by the bOBP represents a complex process

77 that requires particular organization of the secondary and tertiary structures of the bOBP

78 monomers. In other words, we hypothesized that the recombinant bOBP has perturbed packing

79 of its $\alpha$-helical region and some $\beta$-strands, and that these perturbations in packing of the

80 secondary structure elements might affect the formation of native domain-swapped dimer

81 (Stepanenko et al. 2014b).

82 Our previous analysis also revealed that the native dimeric form of the recombinant bOBP

83 is formed under the mildly denaturing conditions (i.e., in the presence of $1.5 \mathrm{M}$ guanidine

84 hydrochloride $(\mathrm{GdnHCl})$ ) (Stepanenko et al. 2014b). This process requires noticeable

85 reorganization of the bOBP structure and is accompanied by the formation of a stable, more

86 compact intermediate state which is maximally populated at $0.5 \mathrm{M} \mathrm{GdnHCl}$. Cooperative

87 unfolding of the recombinant bOBP is induced by the increase of the $\mathrm{GdnHCl}$ concentration

88 above $1.5 \mathrm{M}$, whereas this protein is completed by $\sim 3 \mathrm{M} \mathrm{GdnHCl}$ (Stepanenko et al. 2014b).

89 Thus, in the presence of $\mathrm{GdnHCl}$ at concentrations lower than $1.6 \mathrm{M}$, the protein molecule 
90 undergoes some local structural perturbations rather than the unfolding process. Despite its

91 disturbed fold, the recombinant bOBP is characterized by high conformational stability, which is

92 comparable with that of the native (isolated from tissue) bOBP (Mazzini et al. 2002), pOBP

93 (Staiano et al. 2007; Stepanenko et al. 2008), and other $\beta$-rich proteins (Stepanenko et al. 2012;

94 Stepanenko et al. 2013; Stepanenko et al. 2014a). This high conformational stability is indicated

95 by the fact that the recombinant bOBP unfolding is characterized by the half-transition point of $>$

$962 \mathrm{M} \mathrm{GdnHCl}$ (Stepanenko et al. 2014b; Stepanenko et al. 2015c). We have also established that

97 the unfolding of the recombinant bOBP is a completely reversible process, whereas the

98 preceding process of its dimerization is the irreversible event (Stepanenko et al. 2014b).

99 One of the open challenges in the fields of protein science is the elucidation of the effects

100 of natural cellular environment on protein structure and function, and on the processes of protein

101 folding, unfolding, and aggregation. This challenge is defined (at least in part) by the so-called

102 macromolecular crowding phenomenon, which originates from a known fact that the living cell

103 contains very high concentrations of biological macromolecules (proteins, nucleic acids,

104 polysaccharides, ribonucleoproteins, etc.), which can range from 80 to $400 \mathrm{mg} / \mathrm{mL}$ (Rivas et al.

105 2004; van den Berg et al. 1999; Zimmerman \& Trach 1991). This crowded environment is

106 characterized by the restricted amounts of free water (Ellis 2001; Fulton 1982; Minton 1997;

107 Minton 2000b; Zimmerman \& Minton 1993; Zimmerman \& Trach 1991) and by the limited

108 amount of the space available for a query protein due to the volume occupied by crowders

109 (Minton 2001; Zimmerman \& Minton 1993). In fact, it is estimated that the volume occupancy

110 inside the cell is in a range of 5-40\% (Ellis \& Minton 2003). Therefore, it is expected that in

111 such a crowded milieu, the average spacing between macromolecules should be smaller than the

112 size of the macromolecules themselves (Homouz et al. 2008), and that the macromolecular 
113 crowding should have significant effects on various biological processes that depend on the

114 available volume (Minton 2005; Zimmerman \& Minton 1993).

115 In the laboratory practice, the potential effects of macromolecular crowding on various

116 biological macromolecules and different biological processes are typically analyzed using

117 solutions containing high concentrations of a model "crowding agent", such as polyethylene

118 glycol (PEG), Dextran, Ficoll, or inert proteins (Chebotareva et al. 2004; Hatters et al. 2002;

119 Kuznetsova et al. 2014; Kuznetsova et al. 2015; Minton 2001). Studies in this field revealed that

120 the efficiency of crowding agents might depend on the ratio between the hydrodynamic

121 dimensions (or occupied volumes) of the crowder and the test molecule, with the most effective

122 conditions being those where the crowder and the test molecule occupy similar volumes (Chen et

123 al. 2011; Minton 1993; Tokuriki et al. 2004). Typically, high concentrations of inert crowders

124 have significant effects on conformational stability and structural properties of some proteins

125 (Christiansen et al. 2010; Engel et al. 2008; Kuznetsova et al. 2014; Mittal \& Singh 2013), and

126 may affect various biological processes, such as protein folding, binding of small molecules,

127 enzymatic activity, protein-nucleic acid interactions, protein-protein interactions, protein

128 chaperone activity, pathological protein aggregation, and extent of amyloid formation

129 (Chebotareva et al. 2015a; Chebotareva et al. 2015b; Hatters et al. 2002; Kuznetsova et al. 2014;

130 Kuznetsova et al. 2015; Minton 2000a; Morar et al. 2001; Shtilerman et al. 2002; Uversky et al.

131 2002). For example, we recently conducted a large-scale analysis of the effect of two traditional

132 macromolecular crowders, PEG-8000 and Dextran-70, on the urea-induced unfolding of eleven

133 globular proteins belonging to different structural classes (Stepanenko et al. 2015a). This

134 analysis revealed that crowding agents do not have significant effects on the conformational

135 stability of small, monomeric, positively charged proteins but stabilize oligomeric negatively 
136 charged proteins (Stepanenko et al. 2015a). Since different polymers were shown to have very

137 different effects on the conformational stability of a given protein, it has been concluded that the

138 excluded volume effect is not the only factor influencing the protein behavior in the crowded

139 environments, and that the inequality of different crowders in affecting the conformational

140 stability of proteins can be explained by the ability of the crowding agents to change the solvent

141 properties of aqueous media (Stepanenko et al. 2015a).

142 In the first article of this series we compared structural and functional properties of the

143 recombinant wild type bOBP and its mutants that cannot dimerize via the domain swapping

144 (Stepanenko et al. 2015b). The analysis revealed that none of the amino acid substitutions

145 introduced to the bOBP affected functional activity of the protein and that the ligand binding

146 leads to the formation of a more compact and stable state of the recombinant bOBP and its

147 mutant monomeric forms (Stepanenko et al. 2015b). Second article of the series was dedicated to

148 the analysis of conformational stabilities of the recombinant bOBP and its monomeric variants in

149 the absence and presence of the natural ligand (Stepanenko et al. 2015c). We showed that the

150 unfolding-refolding pathways of the recombinant bOBP and its monomeric forms are similar and

151 do not depend on the oligomeric status of the protein, suggesting that the information on the

152 unfolding-refolding mechanism is encoded in the structure of the bOBP monomers (Stepanenko

153 et al. 2015c). Unfolding of these proteins, recombinant bOBP and its monomeric mutant forms

154 bOBP-Gly121+ and GCC-bOBP, was accompanied by accumulation of an intermediate state that

155 was able to bind ANS and had more compact tertiary structure than the corresponding native

156 states. This intermediate state existed at the pre-denaturing $\mathrm{GdnHCl}$ concentrations, whereas the

157 complete unfolding of these proteins proceeded from the less compact form. In the case of

158 bOBP, the substantial unfolding of the protein precedes the subsequent transition to the native 
159 dimeric state, whereas at high $\mathrm{GdmHCl}$ concentrations, dissociation of this dimer occurs

160 simultaneously with protein unfolding. Furthermore, the previous work indicated that the bOBP

161 unfolding process is significantly complicated by the domain-swapped dimer formation, and that

162 the rates of the unfolding-refolding reactions are controlled by the environmental conditions

163 (Stepanenko et al. 2015c).

164 In this work, we investigated the peculiarities of the unfolding-refolding processes of the 165 recombinant bOBP in the presence of different concentrations of model crowding agents, such as 166 PEGs of different molecular masses. To this end, we looked at the influence of PEG-600, PEG1674000 and PEG-12000 in concentrations of 80,150 , and $300 \mathrm{mg} / \mathrm{mL}$ on the conformational 168 stability of the recombinant bOBP against the GdnCl-induced unfolding.

MATHERIAL AND METHODS

GdnHCl (Nacalai Tesque, Japan), ANS (ammonium salt of 8-anilinonaphtalene-1-sulfonic

173 acid; Fluka, Switzerland) and crowding agents (PEG600, PEG4000 and PEG12000; Sigma-

174 Aldrich, USA) were used without further purification. The protein concentration was $0.1-0.2$

$175 \mathrm{mg} / \mathrm{mL}$. The experiments were performed in $20 \mathrm{mM}$ Na-phosphate-buffered solution at $\mathrm{pH}$ 7.8.

Gene expression and protein purification

The plasmid pT7-7-bOBP which encodes bOBP with a poly-histidine tag were used to

179 transform Escherichia coli BL21(DE3) host (Invitrogen) (Stepanenko et al. 2014b). The protein 180 expression was induced by incubating the cells with $0.3 \mathrm{mM}$ of isopropyl-beta-D-1- 
181 thiogalactopyranoside (IPTG; Fluka, Switzerland) for $24 \mathrm{~h}$ at $37{ }^{\circ} \mathrm{C}$. The recombinant protein

182 was purified with Ni+-agarose packed in HisGraviTrap columns (GE Healthcare, Sweden). The

183 protein purity was determined through SDS-PAGE in 15\% polyacrylamide gel (Laemmli 1970).

\section{Fluorescence spectroscopy}

Fluorescence experiments were performed using a Cary Eclipse spectrofluorimeter(Varian,

Australia) with microcells FLR (10 x $10 \mathrm{~mm}$; Varian, Australia). Fluorescence lifetime were measured using a "home built" spectrofluorimeter with a nanosecond impulse (Stepanenko et al. 2012; Stepanenko et al. 2014b; Turoverov et al. 1998) as well as micro-cells (101.016-QS 5 x 5 mm; Hellma, Germany). Tryptophan fluorescence in the protein was excited at the long-wave

191 absorption spectrum edge $\left(\lambda_{\mathrm{ex}}=297 \mathrm{~nm}\right)$, wherein the tyrosine residue contribution to the bulk

192 protein fluorescence is negligible. The fluorescence spectra position and form were characterized

193 using the parameter $A=I_{320} / I_{365}$, wherein $I_{320}$ and $I_{365}$ are the fluorescence intensities at the

194 emission wavelengths 320 and $365 \mathrm{~nm}$, respectively (Turoverov \& Kuznetsova 2003). The

195 values for parameter $A$ and the fluorescence spectrum were corrected for instrument sensitivity.

196 The tryptophan fluorescence anisotropy was calculated using the equation $197 r=\left(I_{V}^{V}-G I_{H}^{V}\right) /\left(I_{V}^{V}+2 G I_{H}^{V}\right)$, wherein $I_{V}^{V}$ and $I_{H}^{V}$ are the vertical and horizontal fluorescence 198 intensity components upon excitement by vertically polarized light. $G$ is the relationship between

199 the fluorescence intensity vertical and horizontal components upon excitement by horizontally

200 polarized light $\left(G=I_{V}^{H} / I_{H}^{H}\right), \lambda_{\mathrm{em}}=365 \mathrm{~nm}$ (Turoverov et al. 1998). The fluorescence intensity

201 for the fluorescent dye ANS was recorded at $\lambda_{\mathrm{em}}=480 \mathrm{~nm}\left(\lambda_{\mathrm{ex}}=365 \mathrm{~nm}\right)$. Protein unfolding was

202 initiated by manually mixing the protein solution $(40 \mu \mathrm{l})$ with a buffer solution $(510 \mu \mathrm{l})$ that 
203 included the necessary $\mathrm{GdnHCl}$ concentration and crowding agent concentration. The $\mathrm{GdnHCl}$

204 concentration was determined by the refraction coefficient using an Abbe refractometer (LOMO,

205 Russia; (Pace 1986)). The dependences of different fluorescent characteristics bOBP on GdnHCl

206 were recorded following protein incubation in a solution with the appropriate denaturant

207 concentration at $4{ }^{\circ} \mathrm{C}$ for different times (see in the text). The protein refolding was initiated by

208 diluting the pre-denatured protein (in $3.0 \mathrm{M} \mathrm{GdnHCl,} 40 \mu \mathrm{l}$ ) with the buffer or denaturant

209 solutions at various concentrations $(510 \mu \mathrm{l})$, containing crowding agent. The spectrofluorimeter

210 was equipped with a thermostat that holds the temperature constant at $23{ }^{\circ} \mathrm{C}$.

211

212 Circular dichroism measurements

213 The CD spectra were generated using a Jasco-810 spectropolarimeter (Jasco, Japan). Far-

214 UV CD spectra were recorded in a 1-mm path length cell from $260 \mathrm{~nm}$ to $190 \mathrm{~nm}$ with a $0.1 \mathrm{~nm}$

215 step size. Near-UV CD spectra were recorded in a $10-\mathrm{mm}$ path length cell from $320 \mathrm{~nm}$ to 250

$216 \mathrm{~nm}$ with a $0.1 \mathrm{~nm}$ step size. For the spectra, we generated 3 scans on average. The CD spectra for

217 the appropriate buffer solution were recorded and subtracted from the protein spectra.

219 Fitting of denaturation curves

220 The equilibrium dependences of the parameter $A$ on the $\mathrm{GdnHCl}$ concentration were fit

221 using a two-state model (Staiano et al. 2007):

222

$$
S=\frac{S_{N}+S_{U} \alpha K_{N-U}}{1+\alpha K_{N-U}}
$$

$223 \quad K_{N-U}=\exp \left(\frac{-\Delta G_{N-U}^{0}+m_{N-U}[D]}{R T}\right)$, 


$$
K_{N-U}=F_{U} / F_{N}=\left(1-F_{N}\right) / F_{N}
$$

225 taking into account

$$
S_{N}=a_{N}+b_{N}[D]
$$

227

$$
S_{U}=a_{U}+b_{U}[D]
$$

where $S$ is the parameter $A$ at the measured $\mathrm{GdnHCl}$ concentration; $[D]$ is the guanidine concentration; $m$ is the linear dependence of $\Delta G_{N-U}$ on the denaturant concentration; $\Delta G_{N-U}^{0}$ is the

230 free energy of unfolding at $0 \mathrm{M}$ denaturant; $F_{\mathrm{N}}$ and $F_{\mathrm{U}}$ are the fractions of native and unfolded

231 molecules, respectively; $S_{N}$ and $S_{U}$ are the signal of the native and unfolded states, respectively;

$232 a_{N}, b_{N}, a_{U}$ and $b_{U}$ are constants needed to fit linear dependences of the $S_{N}$ and $S_{U}$ signals on the

$233 \mathrm{GdnHCl}$ concentration; and $\alpha=\frac{I_{U, 365}}{I_{N, 365}}$ with $I_{N, 365}$ and $I_{U, 365}$ being fluorescence intensity at 365

$234 \mathrm{~nm}$ for the native and unfolded protein. Fitting was performed using a nonlinear regression with

235 Sigma Plot.

236 Previously, to evaluate conformational stability of the studied proteins we took into 237 account that the formation of the native dimeric state of bOBP occurred at moderate $\mathrm{GdnHCl}$ 238 concentration is followed by full protein unfolding while conformational perturbations of bOBP 239 at low denaturant concentrations were not attributed to the unfolding of the protein globule 240 (Stepanenko et al. 2015c). As bOBP unfolding is fully reversible the transition from native to 241 unfolded state of the protein was used to calculate $\Delta G_{N-U}$ value. Conformational stability of the 242 bOBP in the crowded environment was evaluated similarly as presence of crowding agents 243 resulted in flattering of denaturing curve of bOBP.

244 It is important to emphasize here that the maximal achievable concentrations of denaturant 245 in the presence of crowding agents, especially at their highest tested concentrations, were limited 
246 by the solubility of the protein - denaturant - crowder systems. This limitation determined the

247 number of data-points within the post-transition region.

249 RESULTS AND DISCUSSION

250

251

252

253

254

255

256

257

258

259

260

261

262

263

264

265

266

267

bOBP unfolding in the presence of PEG-600

Previously, we have shown that denaturing curves describing GdnHCl-induced unfolding of bOBP have a complex shape with two clearly distinguishable regions where the pattern of the different protein characteristics diverges significantly (Stepanenko et al. 2014b). In the region above 1.6 $\mathrm{M} \mathrm{GdnHCl}$, the bOBP unfolding took place as indicated by significant and simultaneous changes of all protein characteristics. The moderate structural perturbations of the bOBP with local minimum at $0.5 \mathrm{M} \mathrm{GdnHCl}$ (Figs. $2-4$, red symbols and lines) in the region below 1.6 $\mathrm{M} \mathrm{GdnHCl}$ were designated to the bOBP transition from a mixture of monomeric and dimeric molecules in the absence of denaturant to a native dimeric state through the local reorganization of the bOBP structure in the intermediate state at $0.5 \mathrm{M} \mathrm{GdnHCl}$ (Stepanenko et al. 2014b). The conformational stability of bOBP was described in terms of the half-transition values (2.1 $\pm 0.1 \mathrm{M} \mathrm{GdnHCl}$, see Table 1) (Stepanenko et al. 2015c).

In other words, the formation of the native dimeric state of bOBP takes place at moderate $\mathrm{GdnHCl}$ concentration and is followed by the complete unfolding of this protein, whereas conformational perturbations of bOBP induced by low denaturant concentrations are not attributed to the unfolding of the protein globule. In the absence of $\mathrm{GdnHCl}$, the recombinant bOBP is in a stable state with features similar to the native dimeric bOBP. Still, recombinant bOBP in the absence of $\mathrm{GdnHCl}$ is characterized by a less ordered secondary structure compared 
268 with the wild-type bOBP crystallographic data and a more rigid microenvironment of tryptophan

269 residues. These structural perturbations are responsible for the decreased capability of the

270 recombinant bOBP for dimerization in buffered solutions. We designated this stable recombinant

271 bOBP state in buffered solution as a "trapped" state with incorrect $\alpha$-helical and $\beta$-sheet packing

272 in the protein globule, which may interfere with the formation of the dimeric bOBP native state.

273 The reasons for accumulation of this "trapped" state may lie in a relatively complex domain-

274 swapping mechanism which is required for the monomers to be correctly folded. As a result, in

275 this trapped state bOBP exists as a mixture of monomers and dimers. On the other hand, the

276 intermediate state accumulated at $0.5 \mathrm{M} \mathrm{GdnHCl}$ is characterized by the reorganized the bOBP

277 structure, having fewer ordered secondary structure elements, both $\alpha$-helices and $\beta$-strands,

278 compared to the recombinant bOBP both in a buffered solution and in solution containing $1.5 \mathrm{M}$

$279 \mathrm{GdnHCl}$.

Our analysis revealed that in the presence of low concentrations of PEG-600 $(80 \mathrm{mg} / \mathrm{mL})$, 281 shapes of the curves describing the GdnHCl-induced unfolding of the recombinant bOBP were 282 similar to shapes of the corresponding curves recorded in the absence of crowder. However, the

283 half-transition points for the unfolding curves measured in the presence of PEG-600 were shifted 284 towards the higher $\mathrm{GdnHCl}$ concentrations $\left(C_{\mathrm{m}}=2.4 \pm 0.1 \mathrm{M}\right.$, see Figure $2 \mathrm{~A}$, Table 1$)$. Table 2 285 shows that the values of the parameter $A$ and fluorescence anisotropy $r$ measured for the 286 recombinant bOBP in the presence of $80 \mathrm{mg} / \mathrm{mL}$ PEG-600 were somewhat higher than the 287 corresponding values measured in the absence of crowder. The increase in the PEG-600 288 concentration to $150 \mathrm{mg} / \mathrm{mL}$ resulted in the more pronounced increase in the parameter $A$ and 289 fluorescence anisotropy $r$ values. Figure 2B shows that when the $150 \mathrm{mg} / \mathrm{mL}$ of PEG-600 are 290 added to the solution of the recombinant bOBP, the pre-transition region of the unfolding curve 
291 flattens and the transition happens at higher $\mathrm{GdnHCl}$ concentrations than the unfolding in the

292 presence of the $80 \mathrm{mg} / \mathrm{mL}$ PEG-600 $\left(C_{\mathrm{m}}=2.8 \pm 0.1 \mathrm{M}\right.$, Table 1$)$.

293 Curiously, the curves describing the recombinant bOBP refolding from the completely

294 unfolded state and recorded in the presence of 80 or $150 \mathrm{mg} / \mathrm{mL}$ of PEG-600 did not coincide

295 with the quasi-equilibrium unfolding curves recorded under the similar conditions. However,

296 these refolding curves were close to the curves describing unfolding and refolding of the

297 recombinant bOBP alone (i.e., in the absence of crowding agent; Figure 2A and 2B).

298 Figure $2 \mathrm{C}$ shows that the transition curves describing equilibrium unfolding and refolding

299 of the recombinant bOBP in the presence of $300 \mathrm{mg} / \mathrm{mL}$ PEG-600 coincide and have sigmoidal

300 shape. Furthermore, these transitions happened at significantly higher GdnHCl concentrations

301 than transitions recorded in the presence of 80 or $150 \mathrm{mg} / \mathrm{mL}$ of this crowder $\left(C_{\mathrm{m}}=2.9 \pm 0.1 \mathrm{M}\right.$,

302 Table 1, Figure 6). Table 2 shows that the values of parameter $A$ and fluorescence anisotropy $r$

303 determined in solutions containing $300 \mathrm{mg} / \mathrm{mL}$ PEG-600 were further increased compared to

304 values of these parameters measured at lower PEG concentrations or in the absence of crowding

305 agent. We also observed a slight decrease in the fluorescence lifetime of recombinant bOBP with

306 increasing concentration of PEG-600 from 80 to $300 \mathrm{mg} / \mathrm{mL}$ (Table 1). These data, together with

307 the observed changes in parameter $A$ and fluorescence anisotropy $r$ values, suggested that some

308 compaction of the protein globule took place in the presence of the crowding agent, which

309 resulted in the decrease in a distance between the quenching groups of the protein and its

310 tryptophan residues.

311 Interestingly, the ANS fluorescence intensity, added to the protein solution in the presence

312 of denaturant and PEG-600 at all concentrations tested, remained substantially unchanged

313 (Figure 2). These data are likely to reflect the fact that the presence of this crowding agent 
314 prevents the possibility of the direct interaction of the molecules of low molecular weight dye

315 ANS and the protein.

316

317 bOBP unfolding in the presence of PEG-4000 and PEG-12000

318 Addition of the increasing concentrations of PEG-4000 and PEG12000 was accompanied

319 by the increase in the values of the parameter $A$ and fluorescence anisotropy $r$, as well as the

320 value of fluorescence lifetime (see Table 1). It is worth noting that the value of fluorescence

321 lifetime for recombinant bOBP in the presence of $80 \mathrm{mg} / \mathrm{mL}$ of PEG-4000 significantly below

322 the corresponding value for this parameter for bOBP in the presence of $80 \mathrm{mg} / \mathrm{mL}$ of PEG-

32312000 , and especially in the presence of $80 \mathrm{mg} / \mathrm{mL}$ of PEG-600. However, at elevating the

324 concentration of PEG-4000 and PEG-12000 up to $300 \mathrm{mg} / \mathrm{mL}$ the value of the fluorescence

325 lifetime of recombinant bOBP increased to the values typical of the protein in the presence of

$326300 \mathrm{mg} / \mathrm{mL}$ of PEG-600. These data may reflect the different effect of the crowding agents with

327 diverse molecular weights on the structure of the protein.

328 Curiously, when the unfolding-refolding process of the recombinant bOBP was analyzed in

329 the presence of $80 \mathrm{mg} / \mathrm{mL}$ of PEG-4000 or PEG-12000, the corresponding transitions curves

330 coincided with each other and with curve describing the equilibrium unfolding-refolding

331 processes in the recombinant bOBP alone $\left(C_{\mathrm{m}}=2.3 \pm 0.1 \mathrm{M}\right.$, Table 1, Figure $3 \mathrm{~A}$ and $\left.4 \mathrm{~A}\right)$.

332 Subsequent increase in concentration of PEG-4000 and PEG-12000 to $150 \mathrm{mg} / \mathrm{mL}$ did not

333 change the shape of corresponding curves, but lead to an insignificant and equal for both

334 crowding agents shift of the unfolding transition to higher $\mathrm{GdnHCl}$ concentrations and slight

335 flattering of the pre-trantision regions (see Figures 3B and 4B). Furthermore, the half-transition

336 point for the bOBP unfolding in the presence of $150 \mathrm{mg} / \mathrm{mL}$ of PEG-4000 or PEG-12000 is 
337 observed at a significantly lower $\mathrm{GdnHCl}$ concentrations than in the presence of $150 \mathrm{mg} / \mathrm{mL}$ of

338 PEG-600 $\left(C_{\mathrm{m}}=2.6 \pm 0.1 \mathrm{M}\right.$, Table 1, Figure 6).

339 The half-transition value evaluated in the presence of maximal studied concentration of

340 PEG-4000 and PEG-12000 can not be determined because of the GdnHCl concentrations needed

341 for the complete unfolding of this protein cannot be not reached due to the high viscosity of

342 solutions.. Still, Figure 3C shows that when PEG-4000 concentration was increased to 300

$343 \mathrm{mg} / \mathrm{mL}$ the curve describing the equilibrium unfolding-refolding transitions of bOBP became

344 sigmoidal and coincided with the corresponding curve describing equilibrium unfolding-

345 refolding of this protein in the presence of $300 \mathrm{mg} / \mathrm{mL}$ PEG-600 (see also Figure 6). Although

346 the GdnHCl-induced unfolding curve of the recombinant bOBP in the presence of $300 \mathrm{mg} / \mathrm{mL}$

347 PEG-12000 was also sigmodal (see Figure 4C), the corresponding transition occurred at

348 significantly lower $\mathrm{GdnHCl}$ concentrations (Figure 6).

349 Previously we showed that the recombinant bOBP exists as a mixture of monomeric and

350 dimeric forms because of this protein is in a stable native-like state with reduced dimerization

351 capability (Stepanenko et al. 2014b). The compact dimeric state of the recombinant bOBP is

352 formed under the mild denaturing conditions, namely, in the presence of $1.5 \mathrm{M}$ guanidine

353 hydrochloride $(\mathrm{GdnHCl})$. This process requires bOBP secondary and tertiary structure

354 restructuring and is accompanied by the formation of a stable, more compact, intermediate state

355 that is maximally populated at $0.5 \mathrm{M} \mathrm{GdnHCl}$. In our unfolding-refolding experiment, this state

356 is manifested as a local minimum at $0.5 \mathrm{M} \mathrm{GdnHCl}$ on the $\mathrm{GdnHCl}$ dependences of the bOBP

357 fluorescent characteristics. It worth noting that the fluorescence anisotropy value measured for

358 bOBP in this native dimeric state (i.e. in the presence of $1.5 \mathrm{M} \mathrm{GdnHCl}$ ) exceeds that of bOBP in

359 buffered solution in the absence of denaturant. The presence of crowding agents induced the 
360 increase of the fluorescence anisotropy values of bOBP even in the absence of GdnHCl. This

361 may reflect that crowding agents are able to shift monomer-dimer equilibrium toward the

362 formation of native dimeric bOBP. Flattering of the unfolding curves of bOBP in the presence of

363 elevated concentrations of crowding agents indicates the unfolding of bOBP follows the two-

364 state mechanism without accumulation of any intermediate states. These observations provide

365 further support for the crowding agent-induced reorganization of bOBP to native dimeric state.

366 This effect depends on the crowding agent used and on its concentration.

367 In the case of high concentrations of PEG-4000 and PEG-12000, the high values of 368 parameter $A$ and fluorescence anisotropy $r$, as well as the sigmoid shape of the corresponding 369 unfolding curves testify for the fact that crowding agents stimulates preferential transition of the 370 protein to its native dimeric form. As a result, under these conditions, bOBP unfolds according to 371 the all-or-none model (Figures 4 and 6). However, at lower concentrations of these crowding 372 agents, only slight increase of part of native dimeric state of bOBP occurs.

373 The ANS fluorescence intensity in the presence of PEG-4000 or PEG-12000 shows almost 374 no dependence on denaturant concentration (Figure 3 and 4), which is further support for the 375 interruption of any interaction of the ANS molecules and the protein in the presence of studied 376 crowding agent.

Curiously, similar to the results reported in our previous study (Stepanenko et al. 2015c), analysis of the recombinant bOBP unfolding in the presence of various concentrations of different crowders revealed that the $\mathrm{GdnHCl}$ dependence of various structural characteristics

380 depends on the incubation time of this protein in the presence of the denaturant (see Figures 2-4).

381 In fact, during the unfolding in crowded milieu, equilibrium and quasi-equilibrium values of the

382 analyzed structural characteristics of the recombinant bOBP were reached after the incubation of 
383 this protein in the presence of the desired $\mathrm{GdnHCl}$ concentration for $72 \mathrm{hrs}$. This analysis also

384 revealed the presence of noticeable hysteresis between the curves describing the unfolding and

385 refolding of bOBP when the corresponding measurements were conducted after incubation of the

386 corresponding solution for 1 hour before the measurements (data are not shown).

387 Figure 5A shows that the tertiary structure of the recombinant bOBP was not affected by

388 low concentrations $(80 \mathrm{mg} / \mathrm{mL})$ of PEG-600, PEG-4000, and PEG-12000. However, although

389 the near-UV CD spectra of this protein measured in the presence of high concentrations of

390 crowding agents soon after mixing $(\sim 1 \mathrm{~h})$ were different from the corresponding spectrum

391 measured for bOBP alone (see Figure 5B and 5C), this structural difference disappeared after the

392 prolonged incubation of this protein under the corresponding conditions. The secondary structure

393 of the recombinant bOBP are not changed in the presence of PEG-600, PEG-4000 and PEG-

394 12000, as evidenced by the coincidence of the values of the ellipticity in the far-UV spectrum

395 region recorded for the protein in a buffer solution and in the presence of all crowding agents at

396 all concentrations tested (Figures 2-4).

397 The existence of some dependence of the bOBP structure on the time of incubation in the

398 presence of crowders was further supported by the analysis of the intrinsic tryptophan

399 florescence (see bottom panels in Figure 5). Increase in the incubation time of the recombinant

400 bOBP in the presence of 80 or $150 \mathrm{mg} / \mathrm{mL}$ of crowding agents generates fluorescence spectra

401 that practically coincide with the spectrum of intrinsic fluorescence of the protein alone.

402 However, when concentration of the crowding agents was increased to $300 \mathrm{mg} / \mathrm{mL}$, the intensity

403 of the tryptophan fluorescence was noticeably enhanced. In fact, the intensities of the

404 fluorescence spectra measured in the presence of high concentrations of PEG-4000 and PEG- 
40512000 were slightly higher, and spectra measured in the presence of $300 \mathrm{mg} / \mathrm{mL}$ PEG-600

406 markedly exceeded the bOBP fluorescence intensity in the solution without crowding agents.

407

408 CONCLUSIONS

409 Our analysis revealed that effects of crowding agents on the structural properties of the 410 recombinant bOBP and on the unfolding-refolding processes of this protein depend on the

411 crowder concentration and size. Being added at low concentrations $(80 \mathrm{mg} / \mathrm{mL})$, PEG-600

412 significantly stabilizes the native sate of the recombinant bOBP judging by the dramatic increase

413 in the corresponding half-transition value. However, at low concentrations, PEG-600 did not

414 influence the mechanism underlying the unfolding-refolding process. This is evidenced by the

415 mismatch of the transition curves describing the bOBP unfolding and refolding. Low

416 concentrations $(80 \mathrm{mg} / \mathrm{mL})$ of PEG-4000 and PEG-12000 possess comparable effects - they do

417 not affect the equilibrium unfolding-refolding pathway but lead to moderate increase in the

418 stability of recombinant bOBP to denaturing effects of GdnHCl. The character of changes of the

419 protein fluorescent parameters such as parameter $A$, fluorescence anisotropy $r$, and fluorescence

420 lifetime reflect different modes of action of different crowding agents analyzed in this study. It is

421 likely that some aspects of the PEG-4000 and PEG-12000 action can be associated with the

422 increased solution viscosity in the presence of these agents, whereas PEG-600 may act through

423 some other mechanisms.

424 Moderate concentrations $(150 \mathrm{mg} / \mathrm{mL})$ of crowding agents lead to further increase in the 425 conformational stability of the recombinant bOBP. Under these conditions, PEG-600 possesses

426 more pronounced stabilizing effects than PEG-4000 and PEG-12000 do. At the highest 
427 concentrations of crowding agents analyzed in this study $(300 \mathrm{mg} / \mathrm{mL})$, their effects on bOBP

428 were somewhat changed. In fact, our data show that even in the absence of denaturant, there is a

429 substantial compaction of a protein globule and a shift of the conformational equilibrium towards

430 the native dimeric form of the bOBP. Furthermore, the bOBP unfolding curves measured in the

431 presence of high concentrations of crowding agents become sigmoidal, suggesting that the

432 unfolding of this protein under such conditions can be described as an all-or-none transition.

433 Curiously, these changes were essentially dependent on the size of crowding agents, with PEG-

43412000 possessing smallest stabilizing effects.

435 Therefore, the effect of crowding agents on the structure and conformational stability of 436 the recombinant bOBP depends on two factors: (i) Size of the crowder, with the smaller 437 crowding agents being more effective in the stabilization of the bOBP native dimeric state; and 438 (ii) on the concentration of the crowding agents, with the higher crowder concentrations typically 439 possessing stronger stabilizing effects.

\section{DISCLOSURE}

442 None declared. 


\section{REFERENCES}

444 Bennett MJ, Choe S, and Eisenberg D. 1994. Domain swapping: entangling alliances between

445

446

447

448

449

450

451

452

453

454

455

456

457

458

459

460

461

462

463

464

465

466

467

468

469

470

471

472

473

474

475

476

477

478

479

480

481

482

483

484

485

486 proteins. Proc Natl Acad Sci U S A 91:3127-3131.

Bennett MJ, Schlunegger MP, and Eisenberg D. 1995. 3D domain swapping: a mechanism for oligomer assembly. Protein Sci 4:2455-2468.

Bianchet MA, Bains G, Pelosi P, Pevsner J, Snyder SH, Monaco HL, and Amzel LM. 1996. The three-dimensional structure of bovine odorant binding protein and its mechanism of odor recognition. Nat Struct Biol 3:934-939.

Buck L, and Axel R. 1991. A novel multigene family may encode odorant receptors: a molecular basis for odor recognition. Cell 65:175-187.

Chebotareva NA, Eronina TB, Sluchanko NN, and Kurganov BI. 2015a. Effect of Ca2+ and $\mathrm{Mg} 2+$ ions on oligomeric state and chaperone-like activity of alphaB-crystallin in crowded media. Int J Biol Macromol 76:86-93.

Chebotareva NA, Filippov DO, and Kurganov BI. 2015b. Effect of crowding on several stages of protein aggregation in test systems in the presence of alpha-crystallin. Int J Biol Macromol 80:358-365.

Chebotareva NA, Kurganov BI, and Livanova NB. 2004. Biochemical effects of molecular crowding. Biochemistry (Mosc) 69:1239-1251.

Chen C, Loe F, Blocki A, Peng Y, and Raghunath M. 2011. Applying macromolecular crowding to enhance extracellular matrix deposition and its remodeling in vitro for tissue engineering and cell-based therapies. Adv Drug Deliv Rev 63:277-290.

Christiansen A, Wang Q, Samiotakis A, Cheung MS, and Wittung-Stafshede P. 2010. Factors defining effects of macromolecular crowding on protein stability: an in vitro/in silico case study using cytochrome c. Biochemistry 49:6519-6530.

Dutta S, Burkhardt K, Young J, Swaminathan GJ, Matsuura T, Henrick K, Nakamura H, and Berman HM. 2009. Data deposition and annotation at the worldwide protein data bank. Mol Biotechnol 42:1-13.

Ellis RJ. 2001. Macromolecular crowding: obvious but underappreciated. Trends Biochem Sci 26:597--604.

Ellis RJ, and Minton AP. 2003. Cell biology: join the crowd. Nature 425:27-28.

Engel R, Westphal AH, Huberts DH, Nabuurs SM, Lindhoud S, Visser AJ, and van Mierlo CP. 2008. Macromolecular crowding compacts unfolded apoflavodoxin and causes severe aggregation of the off-pathway intermediate during apoflavodoxin folding. $J$ Biol Chem 283:27383-27394.

Flower DR, North AC, and Sansom CE. 2000. The lipocalin protein family: structural and sequence overview. Biochim Biophys Acta 1482:9-24.

Fulton AB. 1982. How crowded is the cytoplasm? Cell 30:345--347.

Hatters DM, Minton AP, and Howlett GJ. 2002. Macromolecular crowding accelerates amyloid formation by human apolipoprotein C-II. J Biol Chem 277:7824--7830.

Homouz D, Perham M, Samiotakis A, Cheung MS, and Wittung-Stafshede P. 2008. Crowded, cell-like environment induces shape changes in aspherical protein. Proc Natl Acad Sci U $S$ A 105:11754-11759.

Hsin J, Arkhipov A, Yin Y, Stone JE, and Schulten K. 2008. Using VMD: an introductory tutorial. Curr Protoc Bioinformatics Chapter 5:Unit 57. 
487 Kuznetsova IM, Turoverov KK, and Uversky VN. 2014. What macromolecular crowding can do to a protein. Int J Mol Sci 15:23090-23140.

Kuznetsova IM, Zaslavsky BY, Breydo L, Turoverov KK, and Uversky VN. 2015. Beyond the excluded volume effects: mechanistic complexity of the crowded milieu. Molecules 20:1377-1409.

Laemmli UK. 1970. Cleavage of structural proteins during the assembly of the head of bacteriophage T4. Nature 227:680-685.

Liu Y, and Eisenberg D. 2002. 3D domain swapping: as domains continue to swap. Protein Sci 11:1285-1299.

Mazzini A, Maia A, Parisi M, Sorbi RT, Ramoni R, Grolli S, and Favilla R. 2002. Reversible unfolding of bovine odorant binding protein induced by guanidinium hydrochloride at neutral pH. Biochim Biophys Acta 1599:90-101.

Merritt EA, and Bacon DJ. 1977. Raster3D: Photorealistic molecular graphics. . Methods enzymol 277:505-524.

Minton AP. 1993. Macromolecular crowding and molecular recognition. J Mol Recognit 6:211214.

Minton AP. 1997. Influence of excluded volume upon macromolecular structure and associations in 'crowded' media. Curr Opin Biotechnol 8:65--69.

Minton AP. 2000a. Implications of macromolecular crowding for protein assembly. Curr Opin Struct Biol 10:34--39.

Minton AP. 2000b. Protein folding: Thickening the broth. Curr Biol 10:R97--99.

Minton AP. 2001. The influence of macromolecular crowding and macromolecular confinement on biochemical reactions in physiological media. J Biol Chem 276:10577--10580.

Minton AP. 2005. Models for excluded volume interaction between an unfolded protein and rigid macromolecular cosolutes: macromolecular crowding and protein stability revisited. Biophys J 88:971-985.

Mittal S, and Singh LR. 2013. Denatured state structural property determines protein stabilization by macromolecular crowding: a thermodynamic and structural approach. Plos One 8:e78936.

Morar AS, Olteanu A, Young GB, and Pielak GJ. 2001. Solvent-induced collapse of alphasynuclein and acid-denatured cytochrome c. Protein Sci 10:2195--2199.

Nolting B. 1999. Protein folding kinetics. In Biophysical Methods, p 111, Springer-Verlag, Berlin-Heidelberg.

Pace CN. 1986. Determination and analysis of urea and guanidine hydrochloride denaturation curves. Methods Enzymol 131:266-280.

Pelosi P. 1994. Odorant-binding proteins. Crit Rev Biochem Mol Biol 29:199-228.

Pevsner J, Hwang PM, Sklar PB, Venable JC, and Snyder SH. 1988. Odorant-binding protein and its mRNA are localized to lateral nasal gland implying a carrier function. Proc Natl Acad Sci U S A 85:2383-2387.

Pevsner J, and Snyder SH. 1990. Odorant-binding protein: odorant transport function in the vertebrate nasal epithelium. Chem Senses 15:217-222.

Rivas G, Ferrone F, and Herzfeld J. 2004. Life in a crowded world. EMBO Rep 5:23-27.

Shtilerman MD, Ding TT, and Lansbury PT, Jr. 2002. Molecular crowding accelerates fibrillization of alpha-synuclein: could an increase in the cytoplasmic protein concentration induce Parkinson's disease? Biochemistry 41:3855--3860. 
532 Snyder SH, Sklar PB, Hwang PM, and Pevsner J. 1989. Molecular mechanisms of olfaction.

533 Trends Neurosci 12:35-38.

534 Staiano M, D'Auria S, Varriale A, Rossi M, Marabotti A, Fini C, Stepanenko OV, Kuznetsova

535

536

537

538

539

540

541

542

543

544

545

546

547

548

549

550

551

552

553

554

555

556

557

558

559

560

561

562

563

564

565

566

567

568

569

570

571

572

573

574

575 IM, and Turoverov KK. 2007. Stability and dynamics of the porcine odorant-binding protein. Biochemistry 46:11120-11127.

Stepanenko OV, Marabotti A, Kuznetsova IM, Turoverov KK, Fini C, Varriale A, Staiano M, Rossi M, and D'Auria S. 2008. Hydrophobic interactions and ionic networks play an important role in thermal stability and denaturation mechanism of the porcine odorantbinding protein. Proteins 71:35-44.

Stepanenko OV, Povarova OI, Sulatskaya AI, Ferreira LA, Zaslavsky BY, Kuznetsova IM, Turioverov KK, and Uversky VN. 2015a. Protein unfolding in crowded milieu: What crowding can do to a protein undergoing unfolding? J Biomol Struct Dyn:1-0.

Stepanenko OV, Roginskii DO, Stepanenko OV, Kuznetsova IM, Uversky VN, and Turoverov KK. 2015b. Structure and stability of recombinant bovine odorant-binding protein: I. Design and analysis of monomeric mutants. PeerJ.

Stepanenko OV, Roginskii DO, Stepanenko OV, Kuznetsova IM, Uversky VN, and Turoverov KK. 2015 c. Structure and stability of recombinant bovine odorant-binding protein: II. Unfolding of the monomeric forms. PeerJ.

Stepanenko OV, Stepanenko OV, Kuznetsova IM, Shcherbakova DM, Verkhusha VV, and Turoverov KK. 2012. Distinct effects of guanidine thiocyanate on the structure of superfolder GFP. PLoS One 7:e48809.

Stepanenko OV, Stepanenko OV, Kuznetsova IM, Verkhusha VV, and Turoverov KK. 2013. Beta-barrel scaffold of fluorescent proteins: folding, stability and role in chromophore formation. Int Rev Cell Mol Biol 302:221-278.

Stepanenko OV, Stepanenko OV, Kuznetsova IM, Verkhusha VV, and Turoverov KK. 2014a. Sensitivity of superfolder GFP to ionic agents. PLoS One 9:e110750.

Stepanenko OV, Stepanenko OV, Staiano M, Kuznetsova IM, Turoverov KK, and D'Auria S. 2014b. The quaternary structure of the recombinant bovine odorant-binding protein is modulated by chemical denaturants. PLoS One 9:e85169.

Tegoni M, Ramoni R, Bignetti E, Spinelli S, and Cambillau C. 1996. Domain swapping creates a third putative combining site in bovine odorant binding protein dimer. Nat Struct Biol 3:863-867.

Tokuriki N, Kinjo M, Negi S, Hoshino M, Goto Y, Urabe I, and Yomo T. 2004. Protein folding by the effects of macromolecular crowding. Protein Sci 13:125-133.

Turoverov KK, Biktashev AG, Dorofeiuk AV, and Kuznetsova IM. 1998. [A complex of apparatus and programs for the measurement of spectral, polarization and kinetic characteristics of fluorescence in solution]. Tsitologiia 40:806-817.

Turoverov KK, and Kuznetsova IM. 2003. Intrinsic fluorescence of actin. J Fluorescence 13:4157.

Uversky VN, Cooper EM, Bower KS, Li J, and Fink AL. 2002. Accelerated alpha-synuclein fibrillation in crowded milieu. FEBS Lett 515:99--103.

van den Berg B, Ellis RJ, and Dobson CM. 1999. Effects of macromolecular crowding on protein folding and aggregation. EMBO J 18:6927-6933.

van der Wel PC. 2012. Domain swapping and amyloid fibril conformation. Prion 6:211-216. 
576 Vincent F, Ramoni R, Spinelli S, Grolli S, Tegoni M, and Cambillau C. 2004. Crystal structures 577 of bovine odorant-binding protein in complex with odorant molecules. Eur J Biochem $578 \quad 271: 3832-3842$.

579 Zimmerman SB, and Minton AP. 1993. Macromolecular crowding: biochemical, biophysical, $580 \quad$ and physiological consequences. Annu Rev Biophys Biomol Struct 22:27--65.

581 Zimmerman SB, and Trach SO. 1991. Estimation of macromolecule concentrations and excluded 582 volume effects for the cytoplasm of Escherichia coli. J Mol Biol 222:599--620. 
585 Figure 1. 3-D structure of bOBP. The individual subunits in the protein are in gray and pink.

586 The tryptophan residues in the different subunits are indicated in blue and red as van der Waals

587 spheres. The drawing was generated based on the 1OBP file (Tegoni et al. 1996) from PDB

588 (Dutta et al. 2009) using the graphic software VMD (Hsin et al. 2008) and Raster3D (Merritt \& 589 Bacon 1977).

Figure 2. GdnHCl-induced unfolding - refolding of the recombinant bOBP alone (red

592 circles; the data are from (Stepanenko et al. 2014b)) and in the presence of a crowding agent PEG-600 (squares) at low $(80 \mathrm{mg} / \mathrm{mL}, A)$, medium $(150 \mathrm{mg} / \mathrm{mL}, B)$ and high concentration $(300 \mathrm{mg} / \mathrm{mL}, \boldsymbol{C})$. The protein conformational changes were followed by changes in the parameter $A\left(\lambda_{\mathrm{ex}}=297 \mathrm{~nm}\right)$, fluorescence anisotropy $r$ at the emission wavelength $365 \mathrm{~nm}$ $\left(\lambda_{\mathrm{ex}}=297 \mathrm{~nm}\right)$, the ellipticity at $222 \mathrm{~nm}$ and the ANS fluorescence intensity at $\lambda_{\mathrm{em}}=480 \mathrm{~nm}$ $\left(\lambda_{\mathrm{ex}}=365 \mathrm{~nm}\right)$. Protein was incubated in a solution of the desired $\mathrm{GdnHCl}$ concentration at $4^{\circ} \mathrm{C}$ for $24 \mathrm{~h}$ (red circles), $96 \mathrm{~h}$ (green squares) and 7 days (dark yellow squares). The open symbols indicate unfolding, whereas the closed symbols represent refolding.

600

Figure 3. GdnHCl-induced unfolding - refolding of the recombinant bOBP alone (red circles; the data are from (Stepanenko et al. 2014b)) and in the presence of PEG-4000 (squares) at low $(80 \mathrm{mg} / \mathrm{L} A)$, medium $(150 \mathrm{mg} / \mathrm{mL}, B)$ and high $(300 \mathrm{mg} / \mathrm{L} C)$

604 concentration. The protein conformational changes were followed by the changes in the 605 parameter $A\left(\lambda_{\text {ex }}=297 \mathrm{~nm}\right)$, fluorescence anisotropy $r$ at the emission wavelength $365 \mathrm{~nm}$ 
$606\left(\lambda_{\text {ex }}=297 \mathrm{~nm}\right)$, the ellipticity at $222 \mathrm{~nm}$ and the ANS fluorescence intensity at $\lambda_{\text {em }}=480 \mathrm{~nm}$

$607\left(\lambda_{\mathrm{ex}}=365 \mathrm{~nm}\right)$. Protein was incubated in a solution with the appropriate $\mathrm{GdnHCl}$ concentration at $6084^{\circ} \mathrm{C}$ for $24 \mathrm{~h}$ (light green squares and red circles) and $72 \mathrm{~h}$ (green squares). The open symbols 609 indicate unfolding, whereas the closed symbols represent refolding.

611 Figure 4. GdnHCl-induced unfolding - refolding of the recombinant bOBP alone (red 612 circles; the data are from (Stepanenko et al. 2014b)) and in the presence of PEG-12000 613 (squares) at low $(80 \mathrm{mg} / \mathrm{mL}, A)$, medium $(150 \mathrm{mg} / \mathrm{mL}, B)$ and high concentrations $(300$

$614 \mathrm{mg} / \mathbf{m L}, \boldsymbol{C})$. The protein conformational changes were followed by changes in the parameter $A$ $615\left(\lambda_{\mathrm{ex}}=297 \mathrm{~nm}\right)$, fluorescence anisotropy $r$ at the emission wavelength $365 \mathrm{~nm}\left(\lambda_{\mathrm{ex}}=297 \mathrm{~nm}\right)$, the 616 ellipticity at $222 \mathrm{~nm}$, and the ANS fluorescence intensity at $\lambda_{\mathrm{em}}=480 \mathrm{~nm}\left(\lambda_{\mathrm{ex}}=365 \mathrm{~nm}\right)$. Protein 617 was incubated in a solution with the appropriate $\mathrm{GdnHCl}$ concentration at $4^{\circ} \mathrm{C}$ for $24 \mathrm{~h}$ (light 618 green squares and red circles) and $72 \mathrm{~h}$ (green squares). The open symbols indicate unfolding, 619 whereas the closed symbols represent refolding.

621 Figure 5. Changes in the near-UV CD spectra (upper panels) and the tryptophan 622 fluorescence spectra (bottom panels) of bOBP alone (black lines) and in the presence of 623 PEG-600 (green colors), PEG-4000 (red colors) and PEG-12000 (blue colors). The 624 measurements were preceded by incubating the protein in a solution with crowding agent at $4^{\circ} \mathrm{C}$ 625 for $1 \mathrm{~h}$ (PEG-600 - light-green, PEG-4000 - pink, PEG-12000 - light blue) and 72 - 96 h (PEG626600 - green, PEG4-000 - red, PEG-12000 -blue). The concentrations of crowding agents were $62780 \mathrm{mg} / \mathrm{mL}(\boldsymbol{A}), 150 \mathrm{mg} / \mathrm{mL}(\boldsymbol{B})$ and $300 \mathrm{mg} / \mathrm{mL}(\boldsymbol{C})$. 
629 Figure 6. GdnHCl-induced unfolding - refolding of the recombinant bOBP alone (gray 630 circles; the data are from (Stepanenko et al. 2014b)) and in the presence of crowding agents 631 PEG-600 (green colors), PEG-4000 (red colors) and PEG-12000 (blue colors). The protein 632 conformational changes were followed by the changes in parameter $A$ and fluorescence 633 anisotropy at the emission wavelength $365 \mathrm{~nm}\left(\lambda_{\mathrm{ex}}=297 \mathrm{~nm}\right)$. The measurements were preceded 634 by incubating the protein in a solution with the appropriate $\mathrm{GdnHCl}$ concentration at $4^{\circ} \mathrm{C}$ for $72-$ $63596 \mathrm{~h}$. The open symbols indicate unfolding, whereas the closed symbols represent refolding. 636 Applied concentrations of crowding agents were $80 \mathrm{mg} / \mathrm{mL}$ (A; squares, PEG-600 - light green, 637 PEG-4000 - pink, PEG-12000 - light blue), were 150 mg/mL (B; circles, PEG-600 - green, 638 PEG-4000 - red, PEG-12000 -blue) and were $300 \mathrm{mg} / \mathrm{mL}(\boldsymbol{C}$; triangles, PEG-600 - dark yellow, 639 PEG-4000 - brown, PEG-12000 - dark blue). D panel represents all intrinsic fluorescence data 640 for comparison purpose. 


\section{Table $\mathbf{1}$ (on next page)}

Thermodynamic parameters of $\mathrm{GdnHCl}$-induced denaturation of bOBP in the buffered solution and in the crowded environment. 
1 Table 1. Thermodynamic parameters of GdnHCl-induced denaturation of bOBP in the buffered 2 solution and in the crowded environment.

\begin{tabular}{|c|c|c|c|}
\hline $\begin{array}{c}\text { Concentration of } \\
\text { crowding agent }\end{array}$ & $\begin{array}{c}m \\
\left(\mathrm{~kJ} \mathrm{~mol}^{-1} \mathrm{M}^{-1}\right)\end{array}$ & $C_{m}(\mathrm{M})^{\mathrm{a}}$ & $\begin{array}{c}\Delta \boldsymbol{G}^{\mathbf{0}}{ }_{\mathbf{N}-\mathbf{U}} \\
\left(\mathrm{kJ} \mathrm{mol}^{-1}\right)^{\mathrm{b}}\end{array}$ \\
\hline Buffered solution & $3.7 \pm 0.2$ & $2.1 \pm 0.1$ & $-7.7 \pm 0.6$ \\
\hline \multicolumn{4}{|c|}{ PEG-600 } \\
\hline $80^{\mathrm{c}}$ & $4.0 \pm 0.4$ & $2.4 \pm 0.1$ & $-9.3 \pm 1.1$ \\
\hline $150^{\mathrm{c}}$ & $2.9 \pm 0.2$ & $2.8 \pm 0.1$ & $-8.1 \pm 0.6$ \\
\hline 300 & $3.4 \pm 0.4$ & $2.9 \pm 0.1$ & $-9.9 \pm 1.3$ \\
\hline \multicolumn{4}{|c|}{ PEG-4000 } \\
\hline 80 & $3.2 \pm 0.2$ & $2.3 \pm 0.1$ & $-7.4 \pm 0.5$ \\
\hline 150 & $3.2 \pm 0.3$ & $2.6 \pm 0.1$ & $-8.3 \pm 0.8$ \\
\hline \multicolumn{4}{|c|}{ PEG-12000 } \\
\hline 80 & $3.1 \pm 0.2$ & $2.3 \pm 0.1$ & $-7.6 \pm 0.5$ \\
\hline 150 & $3.5 \pm 0.5$ & $2.6 \pm 0.1$ & $-9.1 \pm 1.2$ \\
\hline
\end{tabular}

4

5

6

7

${ }^{a} C_{m}$ is the denaturant concentration at midpoint of conformational transition.

${ }^{b}$ The fluorescence signals of the folded and unfolded states were approximated by linear dependences as function of denaturant concentration (Nolting, 1999).

${ }^{\mathrm{c}}$ Since the unfolding curves of bOBP in the presence of 80 and $150 \mathrm{mg} / \mathrm{ml}$ of PEG-600 are quasi-equilibrium, the conformational stability of bOBP under these conditions was evaluated only for a purpose of comparison. 
Table 2 (on next page)

Characteristics of intrinsic fluorescence of recombinant bOBP alone and in the different crowding agents 
1 Table 2. Characteristics of intrinsic fluorescence of recombinant bOBP alone and in the different 2 crowding agents.

3

\begin{tabular}{|c|c|c|c|c|}
\hline & $\begin{array}{l}\lambda_{\max }, \mathrm{nm} \\
\left(\lambda_{\mathrm{ex}}=297 \mathrm{~nm}\right)\end{array}$ & $\begin{array}{l}\text { Parameter } A \\
\left(\lambda_{\mathrm{ex}}=297 \mathrm{~nm}\right)\end{array}$ & $\begin{array}{l}r \\
\left(\lambda_{\mathrm{ex}}=297 \mathrm{~nm},\right. \\
\left.\lambda_{\mathrm{em}}=365 \mathrm{~nm}\right)\end{array}$ & $\begin{array}{l}\tau, \mathrm{nm} \\
\left(\lambda_{\mathrm{ex}}=297 \mathrm{~nm},\right. \\
\left.\lambda_{\mathrm{em}}=335 \mathrm{~nm}\right)\end{array}$ \\
\hline bOBPwt in buffered solution" & 335 & 1.21 & 0.170 & $4.37 \pm 0.19$ \\
\hline bOBPwt/PEG-600 80 mg/ml & 333 & 1.35 & 0.191 & $4.40 \pm 0.17$ \\
\hline bOBPwt/PEG-600 150 mg/ml & 332 & 1.40 & 0.195 & $4.09 \pm 0.03$ \\
\hline bOBPwt/PEG-600 $300 \mathrm{mg} / \mathrm{ml}$ & 334 & 1.43 & 0.196 & $4.22 \pm 0.03$ \\
\hline bOBPwt/PEG-4000 $80 \mathrm{mg} / \mathrm{ml}$ & 334 & 1.29 & 0.194 & $3.68 \pm 0.25$ \\
\hline bOBPwt/PEG-4000 150 mg/ml & 334 & 1.31 & 0.197 & $3.94 \pm 0.10$ \\
\hline bOBPwt/PEG-4000 300 mg/ml & 335 & 1.37 & 0.20 & $4.19 \pm 0.10$ \\
\hline bOBPwt/PEG-12000 80 mg/ml & 335 & 1.28 & 0.192 & $3.96 \pm 0.04$ \\
\hline bOBPwt/PEG-12000 $150 \mathrm{mg} / \mathrm{ml}$ & 335 & 1.32 & 0.203 & $4.16 \pm 0.07$ \\
\hline bOBPwt/PEG-12000 300 mg/ml & 335 & 1.40 & 0.203 & $4.20 \pm 0.50$ \\
\hline
\end{tabular}

4

$5{ }^{*}$ The data are from (Stepanenko et al. 2014b)

6 The statistical error for fluorescence measurements was assessed and was shown to fall within

7 the range of $0.2-1 \%$. Therefore, the data presented in Table 2 differ significantly. 


\section{1}

3-D structure of bOBP.

Figure 1. 3-D structure of bOBP. The individual subunits in the protein are in gray and pink. The tryptophan residues in the different subunits are indicated in blue and red as van der Waals spheres. The drawing was generated based on the 1OBP file (Tegoni et al. 1996) from PDB (Dutta et al. 2009) using the graphic software VMD (Hsin et al. 2008) and Raster3D (Merritt \& Bacon 1977).

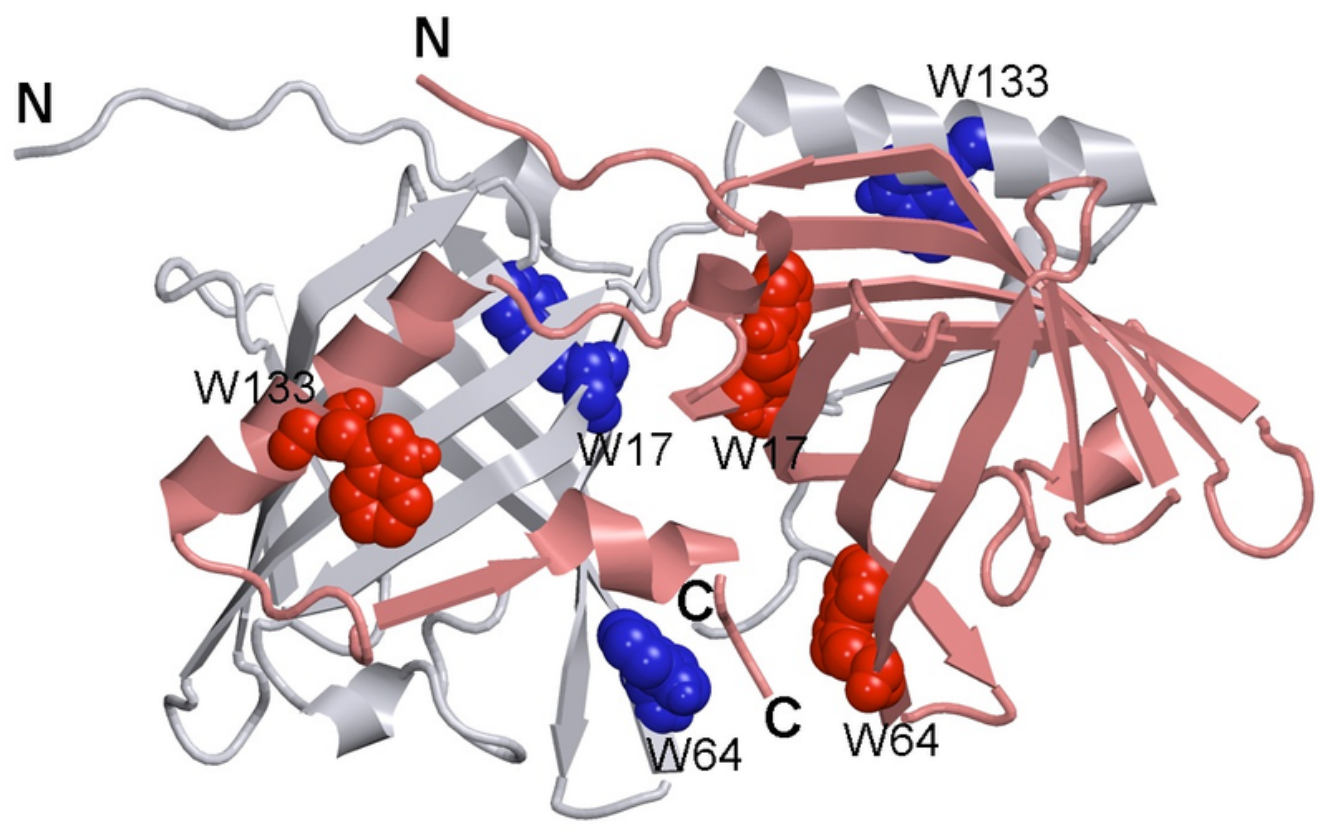


2

GdnHCl-induced unfolding - refolding of the recombinant bOBP alone and in the presence of PEG-600.

Figure 2. GdnHCl-induced unfolding - refolding of the recombinant bOBP alone (red circles; the data are from (Stepanenko et al. 2014b)) and in the presence of a crowding agent PEG-600 (squares) at low $(80 \mathrm{mg} / \mathrm{mL}, A)$, medium (150 mg/mL, $B$ ) and high concentration $(300 \mathrm{mg} / \mathrm{mL}, \mathbf{C})$. The protein conformational changes were followed by changes in the parameter $A\left(\lambda_{\mathrm{ex}}=297 \mathrm{~nm}\right)$, fluorescence anisotropy $r$ at the emission wavelength $365 \mathrm{~nm}\left(\lambda_{\mathrm{ex}}=297 \mathrm{~nm}\right)$, the ellipticity at $222 \mathrm{~nm}$ and the ANS fluorescence intensity at $l_{\mathrm{em}}=480 \mathrm{~nm}\left(\mathrm{l}_{\mathrm{ex}}=365 \mathrm{~nm}\right)$. Protein was incubated in a solution with the appropriate the appropriate $\mathrm{GdnHCl}$ concentration at $4^{\circ} \mathrm{C}$ for $1 \mathrm{~h}$ (gray squares), $24 \mathrm{~h}$ (red circles), $96 \mathrm{~h}$ (green squares) and 7 days (dark yellow squares). The open symbols indicate unfolding, whereas the closed symbols represent refolding. 

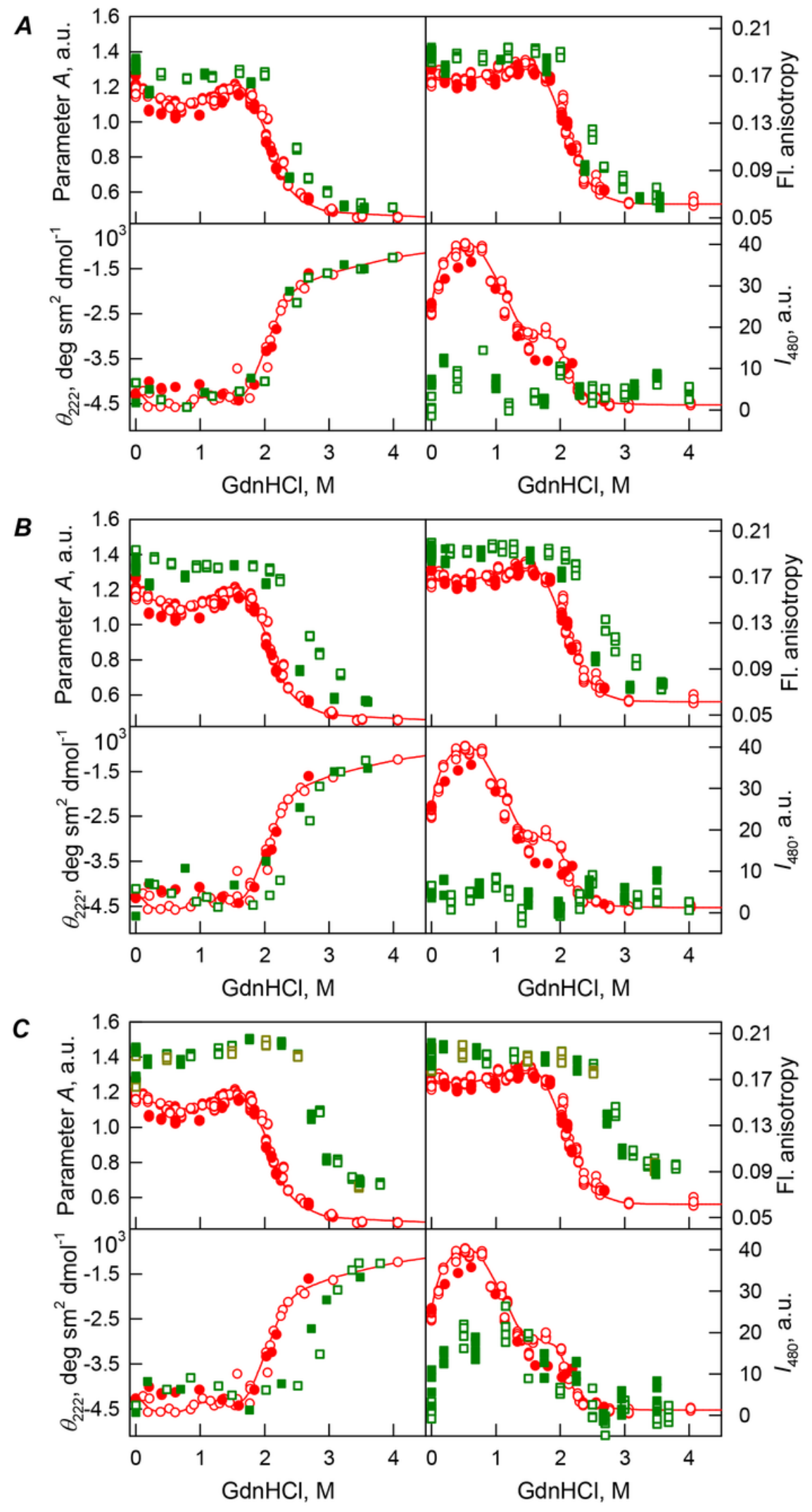


\section{3}

GdnHCl-induced unfolding - refolding of the recombinant bOBP alone and in the presence of PEG-4000.

Figure 3. GdnHCl-induced unfolding - refolding of the recombinant bOBP alone (red circles; the data are from (Stepanenko et al. 2014b)) and in the presence of PEG-4000 (squares) at low (80 mg/L A), medium (150 mg/mL, B) and high (300 $\mathrm{mg} / \mathbf{L} \mathbf{C}$ ) concentration. The protein conformational changes were followed by the changes in the parameter $A$ ( $\lambda_{\mathrm{ex}}=297 \mathrm{~nm}$ ), fluorescence anisotropy $r$ at the emission wavelength 365 $\mathrm{nm}\left(\lambda_{\mathrm{ex}}=297 \mathrm{~nm}\right)$, the ellipticity at $222 \mathrm{~nm}$ and the ANS fluorescence intensity at $\lambda_{\mathrm{em}}=480 \mathrm{~nm}$ $\left(\mathrm{I}_{\mathrm{ex}}=365 \mathrm{~nm}\right)$. Protein was incubated in a solution with the appropriate $\mathrm{GdnHCl}$ concentration at $4^{\circ} \mathrm{C}$ for $1 \mathrm{~h}$ (gray squares), $24 \mathrm{~h}$ (light green squares and red circles) and $72 \mathrm{~h}$ (green squares). The open symbols indicate unfolding, whereas the closed symbols represent refolding. 

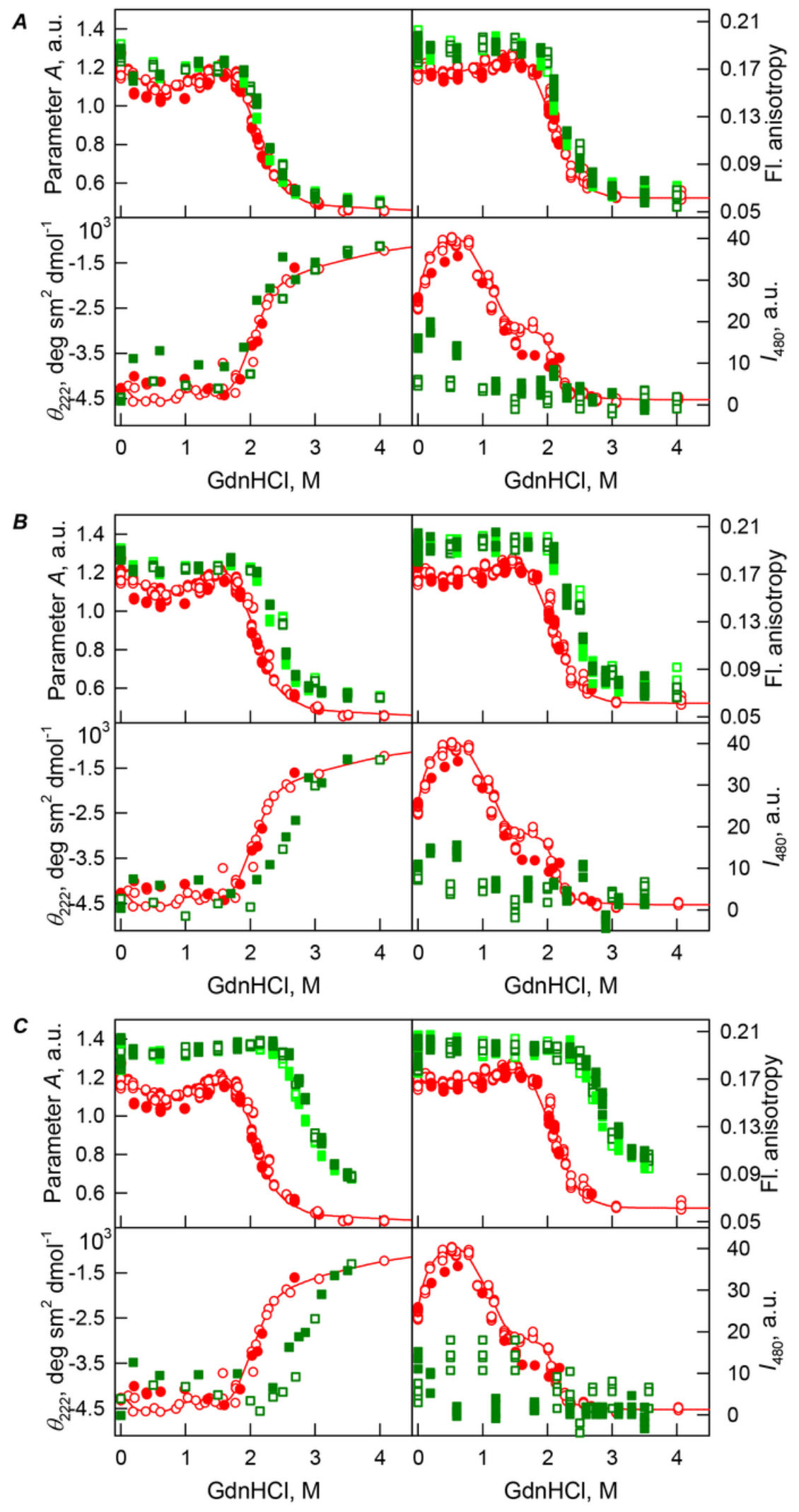


\section{4}

GdnHCl-induced unfolding - refolding of the recombinant bOBP alone and in the presence of PEG-12000 s

Figure 4. GdnHCl-induced unfolding - refolding of the recombinant bOBP alone (red circles; the data are from (Stepanenko et al. 2014b)) and in the presence of PEG-12000 (squares) at low $(80 \mathrm{mg} / \mathrm{mL}, A)$, medium (150 mg/mL, B) and high concentrations ( $300 \mathrm{mg} / \mathrm{mL}, C)$. The protein conformational changes were followed by changes in the parameter $A\left(\lambda_{\mathrm{ex}}=297 \mathrm{~nm}\right)$, fluorescence anisotropy $r$ at the emission wavelength $365 \mathrm{~nm}\left(\lambda_{\mathrm{ex}}=297 \mathrm{~nm}\right)$, the ellipticity at $222 \mathrm{~nm}$, and the ANS fluorescence intensity at $\lambda_{\mathrm{em}}=480 \mathrm{~nm}\left(\mathrm{l}_{\mathrm{ex}}=365 \mathrm{~nm}\right)$. Protein was incubated in a solution with the appropriate $\mathrm{GdnHCl}$ concentration at 4을 $\mathrm{C}$ for $1 \mathrm{~h}$ (gray squares), $24 \mathrm{~h}$ (light green squares and red circles) and $72 \mathrm{~h}$ (green squares). The open symbols indicate unfolding, whereas the closed symbols represent refolding. 

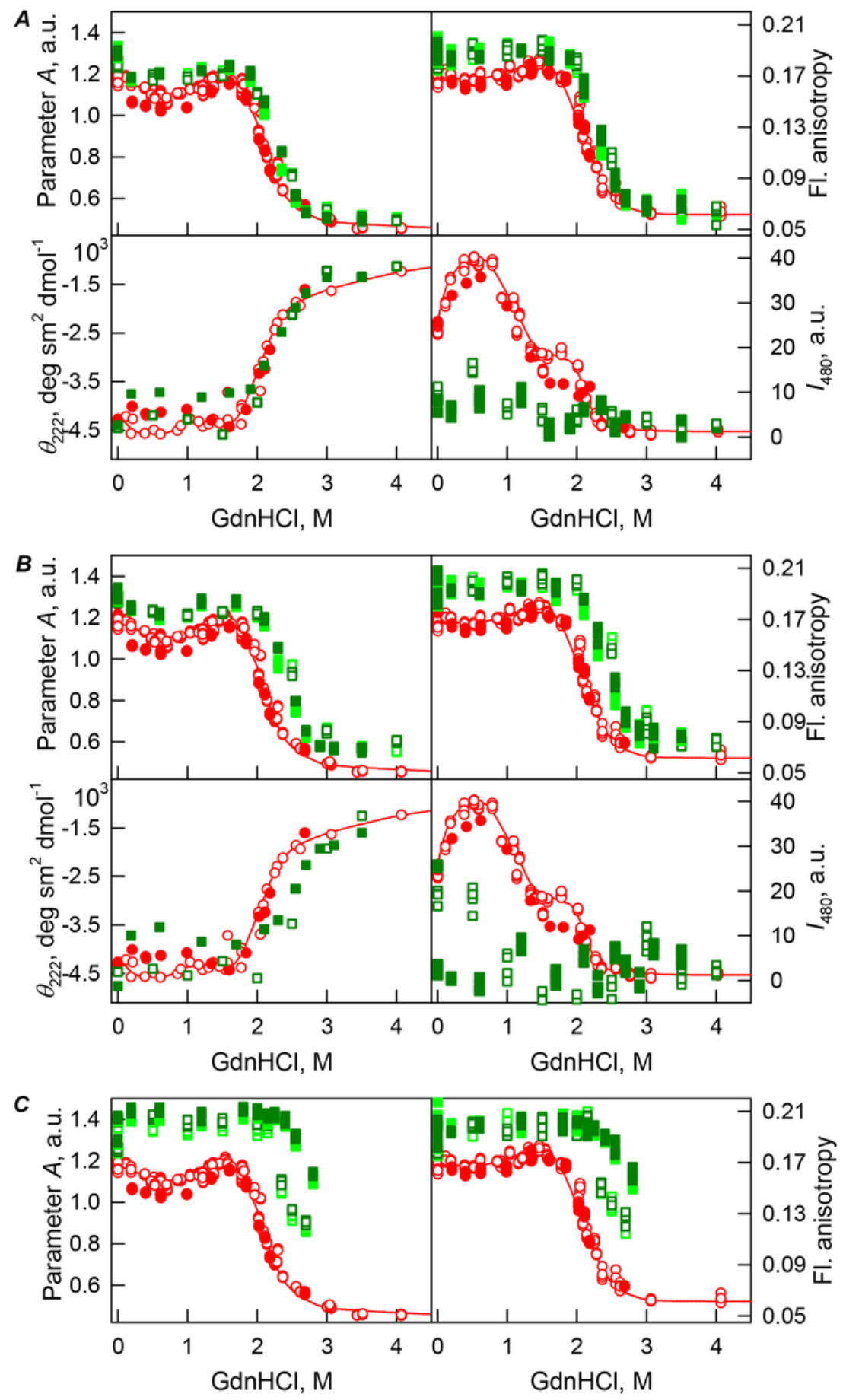
5

Structural properties of bOBP in crowded environment.

Figure 5. Changes in the near-UV CD spectra (upper panels) and the tryptophan fluorescence spectra (bottom panels) of bOBP alone (black lines) and in the presence of PEG-600 (green colors), PEG-4000 (red colors) and PEG-12000 (blue colors). The measurements were preceded by incubating the protein in a solution with crowding agent at 4ำ for $1 \mathrm{~h}$ (PEG-600 - light-green, PEG-4000 - pink, PEG-12000 - light blue) and 72 - 96 h (PEG-600 - green, PEG4-000 - red, PEG-12000 -blue). The concentrations of crowding agents were $80 \mathrm{mg} / \mathrm{mL}(\boldsymbol{A}), 150 \mathrm{mg} / \mathrm{mL}$ (B) and $300 \mathrm{mg} / \mathrm{mL}$ (C).
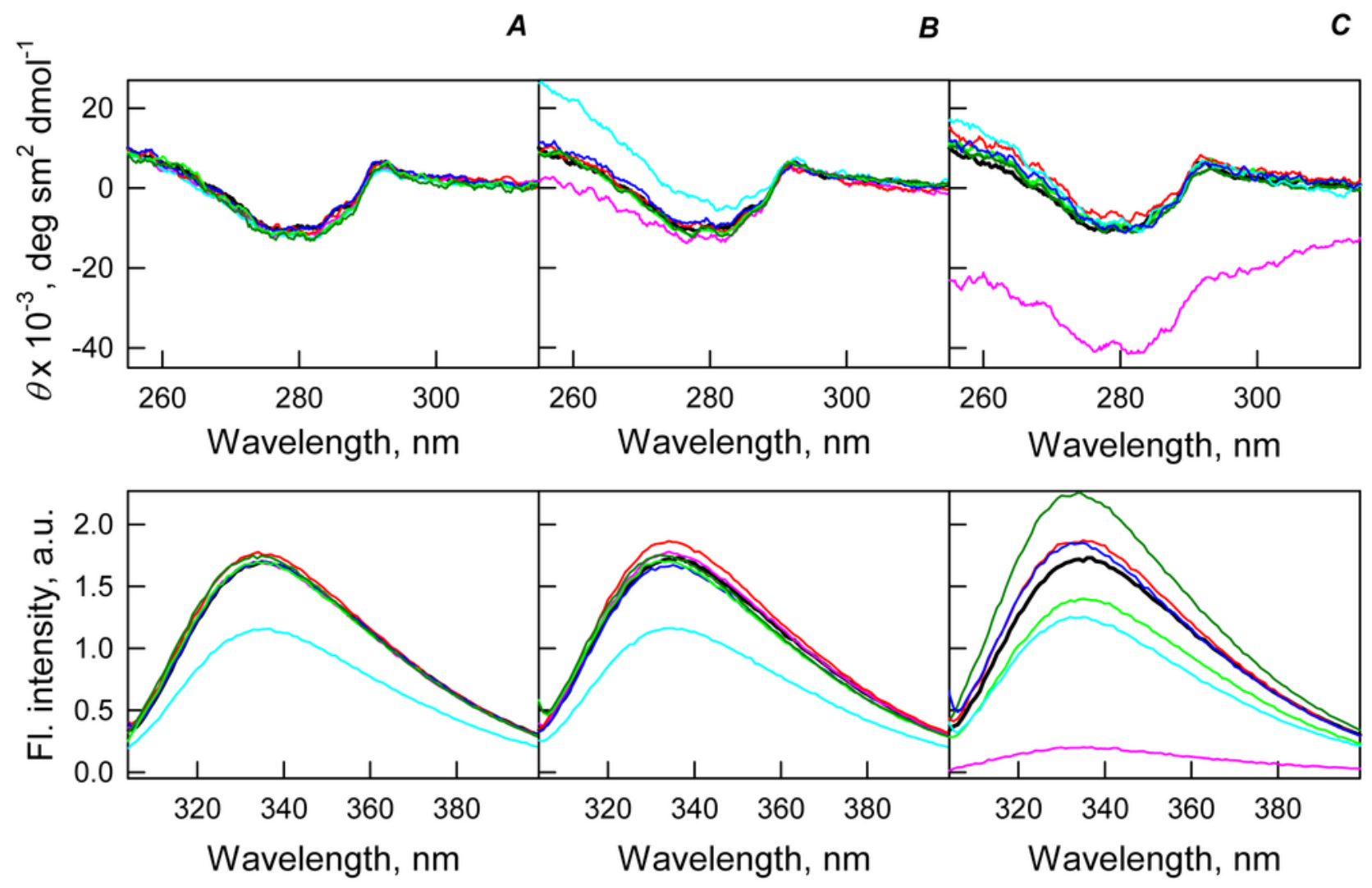
6

GdnHCl-induced unfolding - refolding of the recombinant bOBP alone and in the presence of various crowding agents.

Figure 6. GdnHCl-induced unfolding - refolding of the recombinant bOBP alone (gray circles; the data are from (Stepanenko et al. 2014b)) and in the presence of crowding agents PEG-600 (green colors), PEG-4000 (red colors) and PEG-12000 (blue colors). The protein conformational changes were followed by the changes in parameter $A$ and fluorescence anisotropy at the emission wavelength $365 \mathrm{~nm}\left(\lambda_{\mathrm{ex}}=297 \mathrm{~nm}\right)$. The measurements were preceded by incubating the protein in a solution with the appropriate $\mathrm{GdnHCl}$ concentration at 40 $\mathrm{C}$ for $72-96 \mathrm{~h}$. The open symbols indicate unfolding, whereas the closed symbols represent refolding. Applied concentrations of crowding agents were 80 mg/mL (A; squares, PEG-600 - light green, PEG-4000 - pink, PEG-12000 - light blue), were 150 mg/mL (B; circles, PEG-600 - green, PEG-4000 - red, PEG-12000 -blue) and were 300 mg/mL ( $\boldsymbol{C}$; triangles, PEG-600 - dark yellow, PEG-4000 - brown, PEG-12000 - dark blue). D panel represents all intrinsic fluorescence data for comparison purpose. 


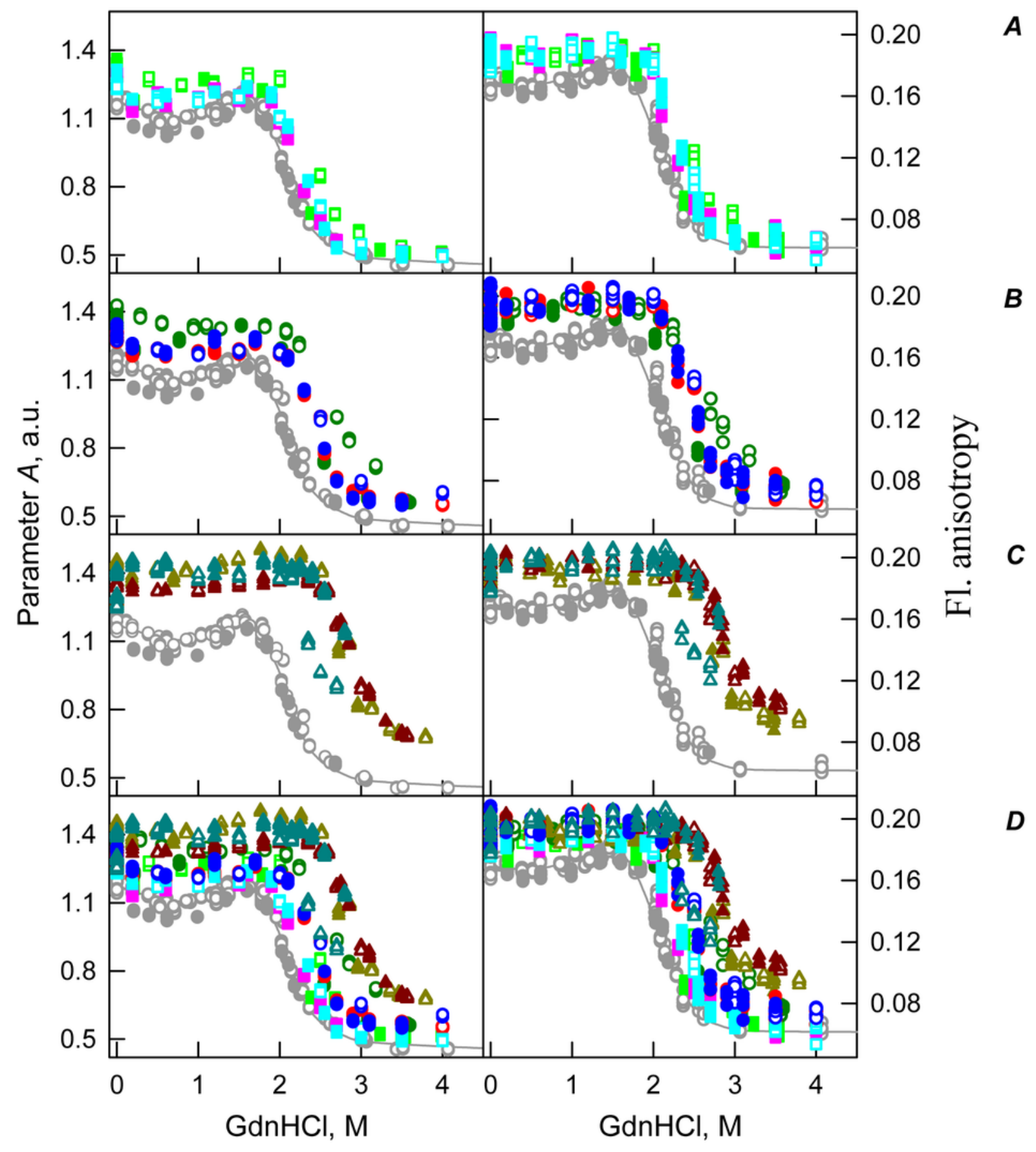

